\title{
Logistics innovation in the medico-social sector: An optimized Workflow for an efficient patient care
}

\author{
HayfaZgaya, Thomas Barras, Alain Durocher \\ Institute of Engineering in Health of Lille, EA 2694, University of Lille 2, France \\ hayfa.zgaya@univ-lille2.fr \\ SECA GROUP, France \\ thomas.barras@groupe-seca.com \\ Institute of Engineering in Health of Lille, EA 2694, University of Lille 2, France \\ alain.durocher@univ-lille2.fr
}

\begin{abstract}
The issue of care for the elderly is a real challenge for our society. The French government offers solutions to users, particularly through institutions hosting for dependent elderly people (nursing homes). We position ourselves in this study in the field of health logistics. We are particularly interested in the implementation of an innovative tool to provide, in realtime, the best possible organization of resources for an efficient patient care. For that, we propose a software solution in the form of a dynamic dashboard, in order to represent and optimize the overall behaviour of a nursing home and especially in terms of resource allocation. This allocation should be in accordance with the workload, patient needs and time constraints. The results show the effectiveness of our solution compared to an intuitive organization based on the experience and the organizational strategies of staff.
\end{abstract}

\section{Indexingterms/Keywords}

Healthcare logistics, healthcare management, modelling, organization, workflow, optimization.

\section{Academic Discipline And Sub-Disciplines}

Healthcare Logistics; medico-social sector

\section{SUBJECT CLASSIFICATION}

Computer science

\section{TYPE (METHOD/APPROACH)}

Workflow modelling;scheduling algorithm

\section{Council for Innovative Research}

Peer Review Research Publishing System

Journal: INTERNATIONAL JOURNAL OF COMPUTERS \& TECHNOLOGY

Vol 11, No. 9

editor@cirworld.com

www.cirworld.com, member.cirworld.com 


\section{INTRODUCTION}

News Healthcare is a wealth of information. However, a topic comes up regularly: older people often referred to as 'dependent'. Our seniors' age and their number is growing. This is all the more worrying that aging inevitably accompanied by a loss of autonomy.

To meet the needs of users, the French government offers a number of solutions ranging from maintaining the accommodation home via temporary accommodation until permanent accommodation institution. We focus on the latter type of accommodation, especially for Institutions Accommodation for Dependent Elderly (nursing homes). Nursing homes have the particularity to offer permanent housing while ensuring monitoring and medical management. The professionals involved in this kind of structure come from different backgrounds, and their coordination is essential.

On the other hand, the law of the medico-social sector is very rich and has continued to evolve. These requirements affect different themes, such as the rights and freedoms of users who are placed in the focus of the functioning and the organization of structures. A balance must be found between community life and respect for the wishes and desires of each, which affects the overall organization of the institution.

On the economic level and according to the current crisis, funding for these structures is scarce and renewal agreements are delayed. These agreements allow normally an update of the resources allocated so that they are aligned with the needs of residents. However, institutions are forced to function with the same quantity of resources, but integrating an increasingly heavy patient care. In this context, the search for organizational strategies and sharing of resources is a challenge.

We position ourselves in this study in the domain of the health logistic. We are particularly interested in the usage of innovative logistic tools in order to achieve the best possible organization of a nursing home for an effective patient care.

The French Association for Logistics (ASLOG) defines logistics as 'the art and the way to provide a given product at the right time, right place, with the lowest cost and the best possible quality.'

In this context, the main objective of our work is to use innovative logistics tools, in the most effective way, to offer patients of a nursing home an effective care and thus provide them the right care at the right time, with the lowest cost and with the best possible quality of service. This is to optimize the distribution of the workload (based on different types of resources) induced by residents whose desires and wishes must be respected.

The used logistic tools must generate a solution which organizes effectively human and material resources of a nursing home. This solution must satisfy some constraints induced by the management of the establishment and the patient care:

1. The establishment and all staff must continually make to better respond to the wishes, desires, rights and freedoms of the supported patients.

2. The adequate staff must be present at the right time, right place and in sufficient numbers.

3. The staff should not have too much free time. However, time issues and work breaks must respect the labour rights and the various collective agreements.

It should be noted that in this study, we focus on the operation of a nursing home and especially on all tasks related to the care and support of residents, excluding administrative, catering, laundry and maintenance tasks. The considered period is a typical day not including night work and the regulatory constraints on cycles.

Before presenting our contribution, we present in the following section a state of the art concerning health logistics problems and their correspondent proposed solutions. In the third part, we justify the adopted approach used to realize the logistic tool presented in the fourth section. In the fifth part of this paper, we prove the effectiveness of the proposed solution. Finally, we conclude the paper in the sixth section where we expose some prospects.

\section{STATE OF THE ART}

The Logistic problems in the healthcare environments are essentially the same that those in the industry field; we have to reach the best possible organization according to the needs, effectively distributing the material and human resources in terms of availability and skills.

Nowadays, one of the most important healthcare logistics issues is to find the most efficient way for the patient care in the health facilities. The patient journey can be likened to a production line with various constraints such as the time and skills management to perform a treatment.

However, and by analogy with the logistic problems in industry, the work (care) is not made on 'items' but on human whose wishes and needs must be respected. Then, we cannot predict accidents and emergencies.

In 2011, Daknou[1] proposes in his thesis an agent based Decision Support System (DSS) integrating optimization algorithms. This system, developed for the emergency of CHR of Lille, aims to distribute efficiently the workload of the various members of the medical team knowing that this distribution takes into account their availability, skill level and emergency levels of patients. The proposed solution is mainly adapted to the dynamic nature of the medical teams. In fact, teams must be formed and deformed in real time to support patients simultaneously. These teams are not static but may exchange personnel as needed. A state of the art of methods and applications for workforce planning was introduced in 2004 by Ernst et al. [2]. 
On the other hand, the workload repartition to the nurses' staff was studied with interest. Again, the use of optimization algorithms allows an efficient allocation of the workload, taking into account the various constraints of the institution in real time. A state of the art on the distribution of nurses' workload was done by Cheang et al. 2003 [3] then by Burke et al. en 2004 [4]. Since then, many studies emerged using several types of algorithms based on various kinds of constraints that depend on the establishment. For example in 2013, Hadwan et al.[5] propose a harmony search algorithm which is a metaheuristic which has to find, for each musician, the perfect harmony in a musical orchestra. Each musician corresponds to a decision variable which has to have the best possible value. This work has provided good results compared with the solutions found in the literature for the same problem.

Regarding the scheduling of tasks in the Operating Room (OR), a tool was developed by Chandoul et al. in 2012 [6]to the hospital in Maubeuge in France. The proposed solution based on a genetic algorithm which is a metaheuristic inspired from the theory of evolution (Fig 1). The model has been implemented and has proven its effectiveness: it sets the most optimal organization of tasks in the OR taking into account its constraints.

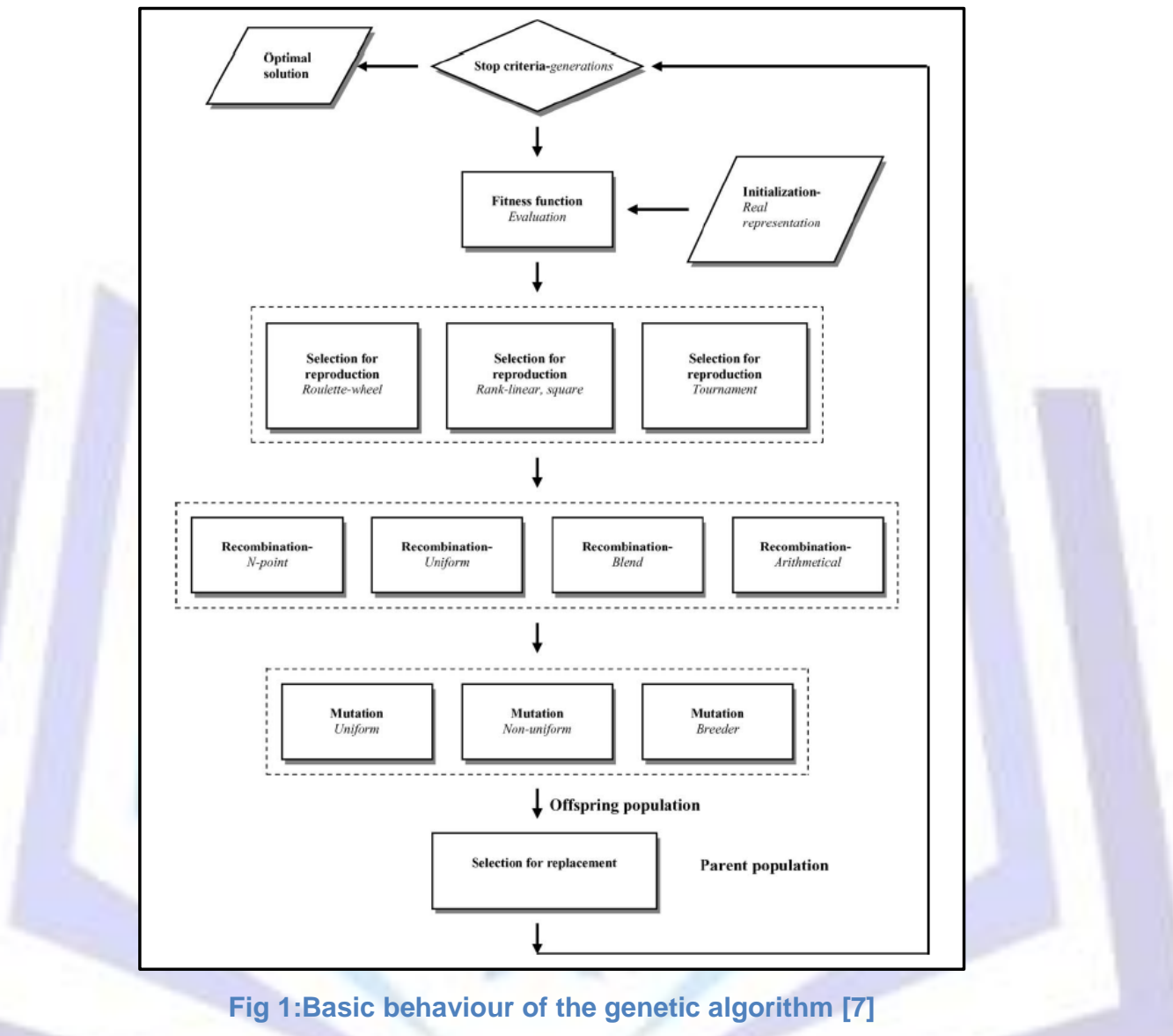

Issues related to health logistic do not just stop to DSS for workload planning and task scheduling. They also concern drugs. Indeed, the management of medical equipment in health facilities is also one of the most important logistic issues today in the field of health. Hassan's thesis in 2006 [8], helped to organize the overall management of medical equipment. In fact, on the basis of a model of Logistics (LC) Chain in hospital, the flow of materials, supplies and medicines have been optimized. The thesis of Di Martinellyin 2008 [9], presents a modelling framework to help decision makers to reorganize and assess their pharmaceutical LC, taking into account the patient flow.

So, to solve logistic problems, new tools for decision support are beginning to be developed and used in the field of health. These tools, which we call innovative logistics tools, are based on complementary modelling and optimization techniques. Modelling is used to represent a system with its components (actors, objects, etc.) and its internal and external interactions. Optimization, in turn, allows finding the best possible strategy to adopt, taking into account a set of criteria and constraints.

There is still no work dealing with the use of logistic tools in the medico-social sector. However, we are inspired from what has been done in the literature, in particular on the complementarities between modelling and optimization approaches and tools.

In what follows, we justify the use of tools and methods used for the implementation of the proposed solution presented in the fourth section. 


\section{METHODS: INNOVATIVE LOGISTIC TOOLS}

According to the state of the art presented in the previous paragraph, new logistic means emerge, specifically in the health field, and are of two types. Firstly, the tools to represent the behaviour of an organization, to map its functioning and to translate its available resources, but also the constraints placed on it. This is the principle of modelling. With the latter, the existing organization can be tested by simulate normal functioning (permanent mode) or disturbed functioning (transient mode). Finally, coupled with the modelling, optimization tools can also be used. The purpose of this complementarity is clearly to represent a system (via a template) before optimizing its functioning.

These new tools, which we call innovative logistic tools, are able to design complex systems, considering the behaviour of their actors, the flow exchange, the resource utilization, etc. and optimize the system performances in accordance with the correspondent constraints and objectives.

\section{The modelling}

To best represent the functioning of an establishment, we have first to determine the most appropriate modelling logistic method according to the purpose.

\section{Selection of the method}

There are many methods to model and analyze logistics system in the health domain [10]. Among these methods, those that can effectively represent today's logistic systems are classified into two categories: the process oriented Approaches (POA) and the Agent Oriented Approaches(AOA) [11, 12]. Compared to the POA, the AOA is centred on the rational and social behaviours of a system's components. The aim of our modelling is not the behaviour analysis of each actor (resident, nurses, etc.) but that the global functioning of the system. So the AOA is not the most suitable approach. Thus we choose the POA, and especially the workflow technology.

\section{The POA and the Workflow}

The best-known approaches for modelling the organizations are: ARIS (Architecture of Integrated Information System) [13, 14], SCOR (Supply Chain Operations Reference-model) [15] and ASCI (Analyse, Specification, Conception et Implementation) [16]. However, the trend is now towards a modelling process that visually represents the activities of organizations as 'active flowcharts'. This discipline uses today the acronym BPM 'Business Process Management'. It gives to an organization the means to control and manage its business processes and not just to model them. Hence the appearance of the GRAI method [17] that especially focuses on the decision-making aspects of the processes. Another more recent approach, corresponding to a new type of modelling has emerged. It is called 'electronic business process management' more known as the workflow. This technique, dedicated to business processes, can represent a system and then implement it, basing on the graphic language BPMN. We adopted this technique because it is the most adapted approach to our objective modelling. In fact, the workflow creates a model representing the behaviour of a system and then implements with integrated engine. During the application, the workflow allows human actors to interact at the right time in reading and/or writing with the system through GUIs. In reading: in order to have the right information at the right time to perform current tasks. In writing: in order to promptly give the system necessary data for an efficient running.

\section{The BPMNlanguage and the Workflowtool}

The Business Process Modelling Notation(BPMN) is a graphical language standardized by the BPMI (Business Process Management Initiative) [18] in order to design and manage business processes [19]. Devices using this type of language correspond to the Workflow tools. These latter can be equipped with a simulation module in order to verify the progress of processes in a system, examining the consumption of human and material resources. An interesting comparison of these tools has been done by Liu et al. in 2011 [20]. Among these tools, we chose Bonitasoft1 qui which has the advantage, in addition to being free, to have the possibility to implement the model with an integrated engine, automatically generate interfaces to allow human interaction with the system and finally simulate this latter thanks to its simulation tool. In addition, this tool allows the link of the system with other external, through connectors.

The basic graphical items to represent a workflow model (the BPMN language) are (Fig 2): the events (start, intermediary and end), gateways (and, inclusive/exclusive or), tasks (human, service, sub-processes, etc.), lanes (representing processes and can be subdivided of pools), artefacts (decoration objects) and the connection items (different types of arrows to connect the other items of the workflow).

So, we adopted this approach to model the organization of a nursing home in terms of business processes. The result of the modelling is presented in the second part of the fourth section and the link with the optimization is highlighted through the general system architecture presentedin the first part of the fourth section.

\footnotetext{
${ }^{1}$ http://www.bonitasoft.com
} 


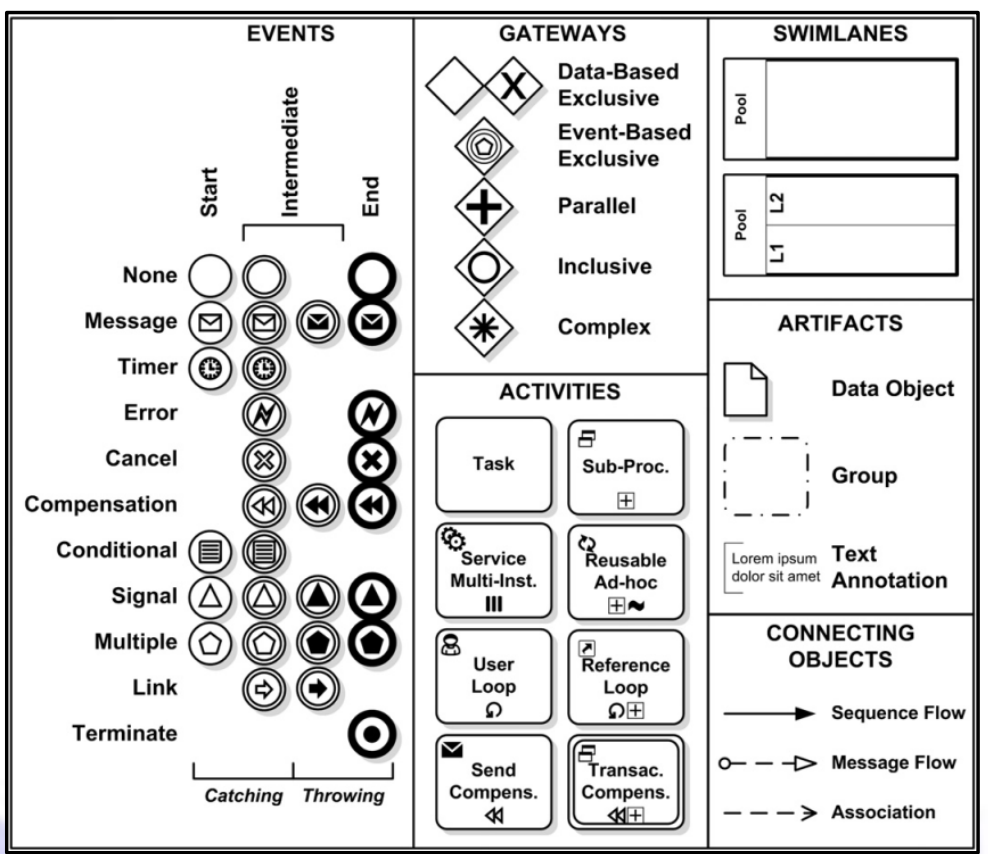

Fig 2: Basic items of the BPMN language [18]

\section{The optimization}

\section{Basic concepts and positioning}

Optimization addresses issues that can be expressed as functions (size dependent on one or more variables) or algorithms with varying complexity. It has ancient origins, but it was really developed from the twentieth century, when it appeared the concept of stock management (with the formula of economic lot).

Then, we looked for ways and techniques to make a decision and get the best possible result, so the decision-making tools; thus was born the Operations Research (OR). The goal is to successfully analyze complex situations in order to assess the issues that depend on them and so make appropriate choices. Specifically, the OR tools aim to find the optimal value, called optimum corresponding to the minimum or maximum of an Objective Function (OF). The latter is based on a set of decision variables (DV) which are selected to optimize a number of criteria (time, cost, etc.). The choice of these DV must be done respecting a set of Equality and Inequality Constraints (EC and IC). All these constraints delimit the search space for the optimal solution.

Formally [21, 22], an optimization problem is in the following form :

Minimizing $f(\overrightarrow{x)}$ (the OF to optimize) with :

- $\quad \vec{x} \in \mathbb{R}^{n}$ : regroups the (n) DV

- $g\left(\overrightarrow{x)} \in \mathbb{R}^{m}:\right.$ regroups the (m) IC

$$
\text { ○ } g(\vec{x}) \leq 0
$$

- $h\left(\overrightarrow{x)} \in \mathbb{R}^{p}:\right.$ regroups the (p) EC

$$
\text { - } h(\overrightarrow{x)}=0
$$

There are several types of optimization problem, depending on the characteristics of the problem issues: the number and the type of DV, the type of the OF and the type of the problem (formulated with or without constraints). This classification is summarized in the Error! Reference source not found.[23].

In the field of the OR, two types of problems exist: strategic issues (finding, based on various constraints and objectives, the best solution) and operational problems (determining the order of execution of many tasks). The problem we address in this study is both strategic and operational. Indeed, the goal is to efficiently allocate human and material resources to the care tasks: optimizing time and workload (2 objectives), basing on time and resource constraints (2 constraints). Therefore, the DV correspond to the dates of the beginning and the end of the different care tasks.

Depending on its complexity, solving this kind of problem requires the use of scheduling approaches, accurate and/or approximate. We are talking here about combinatorial optimization.

To summarize, the problem we deal with in this study is multi-variable, combinatorial, non-linear, constrained and multiobjective. 
Table 1.The optimization problems classification [23]

\begin{tabular}{|c|c|c|c|}
\hline \multicolumn{3}{|c|}{ Problem characteristics } & Type \\
\hline \multirow{5}{*}{$\begin{array}{c}\text { Decision } \\
\text { variable (DV) }\end{array}$} & \multirow{2}{*}{ Number } & 1 & Mono-variable \\
\hline & & $>1$ & Multi-variable \\
\hline & \multirow{3}{*}{ Type } & $\begin{array}{l}\text { Continuous } \\
\text { real number }\end{array}$ & Continuous \\
\hline & & Integer & Discrete \\
\hline & & $\begin{array}{l}\text { Permutation of } \\
\text { a finite set of } \\
\text { numbers }\end{array}$ & Combinatory \\
\hline \multirow{3}{*}{$\begin{array}{l}\text { Objective } \\
\text { function }\end{array}$} & \multirow{3}{*}{ Type } & $\begin{array}{l}\text { Linear } \\
\text { function of DV }\end{array}$ & Linear \\
\hline & & $\begin{array}{l}\text { Quadratic } \\
\text { function of DV }\end{array}$ & quadratic \\
\hline & & $\begin{array}{l}\text { Non-linear } \\
\text { function of DV }\end{array}$ & non-linear \\
\hline \multirow{2}{*}{$\begin{array}{c}\text { Problem } \\
\text { Formulation }\end{array}$} & \multirow{2}{*}{ Type } & $\begin{array}{l}\text { With } \\
\text { constraints }\end{array}$ & $\begin{array}{l}\text { with } \\
\text { constraints }\end{array}$ \\
\hline & & $\begin{array}{l}\text { Without } \\
\text { constraints }\end{array}$ & $\begin{array}{l}\text { without } \\
\text { constraints }\end{array}$ \\
\hline
\end{tabular}

\section{Multi-objective problemresolution}

There are several methods for solving multi-objective problems [21] :

- Interactive methods: these are progressive methods of finding a single solution at a time. Users can set their preferences before or during or optimization process, according to a compromise between the objectives

- Fuzzy methods: these are methods that involve fuzzy logic [24] to solve of multi-objective optimization problems. Unlike classical logic, where everything is described in binary manner (true or false), fuzzy logic can handle the uncertainty, vagueness and the transitions between states in human knowledge. This logic is based on fuzzy sets and was developed by Zadeh[25].

- Decision support methods: these are the only methods dedicated to solve multi-objective optimization problems and which work only on discrete sets of points, and are not based on dominance relations. These methods generate a set of solutions by establishing an order relation between the different elements.

- The Metaheuristics: it is a large family of optimization methods to solve difficult problems: combinatorial optimization problems with discrete variables and global optimization problems with continuous variables. These methods are characterized by a high level of abstraction, which allows them to be adapted to a wide range of problems, from simple local search algorithms to complex global search algorithms. There are several types of metaheuristics :

○ Method of local search: e.g. simulated annealing and tabu search.

- Constructive approach: allow to reduce the size of the problem, at each stage, in order to progressively restrict the set of possible solutions.

- Evolutionary Approaches:

- Evolutionary algorithms: e.g. genetic algorithms and dispersed research

- Ant Colony Algorithms.

Hybrid approaches: the combination of evolutionary algorithms with local search algorithms can produce interesting results.

\section{The methodselection}

In this study, we chose to adopt the metaheuristics and especially evolutionary algorithms to optimize the scheduling of resources required to perform the care tasks in a nursing home. Indeed, these algorithms have been very successful in solving combinatorial optimization problems, in particular the scheduling problems [26, 27]. There are several possible 
algorithms based on metaheuristics. We chose to use Genetic Algorithms (GA) thanks to the flexibility of this approach, its efficiency and its controllable time calculation [28, 29].

Knowing that an individual represents a solution, the principle of this algorithm is presented by theFig 1 : from a starting population of individuals, being evaluated, the best individuals are selected to undergo crossover and mutation operations. Following this operation, the best individuals are kept, and so on. The probabilities of mutation and crossover should be adjusted to achieve better results. The execution time of the algorithm depends on the number of iterations, that is to say, the number of generations. Finally, the algorithm provides the best solution found through all generations. In general, followers of GA prefer to keep a classified archive of best solutions.

Finally, being based on metaheuristics, this type of algorithm is used to test a large number of opportunities at the same time (the individuals in the population), and does not stop at the minimum (or maximum) local solution. Indeed, the constraints imposed by the residents and resources in a nursing home do not involve a single operation: several solutions may be possible. The algorithms not using metaheuristics will stop at the first solution found. The genetic algorithm searches all existing solutions (within the limits of a fixed number of iterations) and determines the best, that is to say, the global optimum.

\section{RESULTS}

\section{The system architecture}

We remind that the objective of our work is to create a DSS to provide, in real time, the best possible organization of human and material resources for an optimal quality of care of the patients in nursing homes. We named this DSS "OWS" for "Optimized Workflow System". Its architecture is shown in the Fig 3and discussed in the following.

Firstly, we model the global organization of the nursing home (the different process) using the POA. The result of this step is a workflow Model (1). We associate with this model an optimization tool called the optimizer (2). This latter is based on an evolutionary algorithm allowing efficient scheduling of human and material resources to perform the care tasks. Thus, the optimizer generates in real-time the optimal allocation of the resources, taking into account the constraints of the establishment (availability of resources, deadlines, etc.). The result of this optimization is then injected into the model and implemented by the workflow engine (3). This latter allows, through fixed or mobile computer devices, (Smartphone, tablet, etc.) to disseminate the workplan of each actor (4). The application must provide the right information to the right resource at the right time to complete the tasks that were assigned to him (this is the innovative logistics). These same devices also allow the human resources to interact with the tool by entering the necessary information in order to ensure the good sequence of activities and exchanged data flows to reach an effective collaboration organization. The system interaction with human resources through these computing devices interfaces is detailed later.

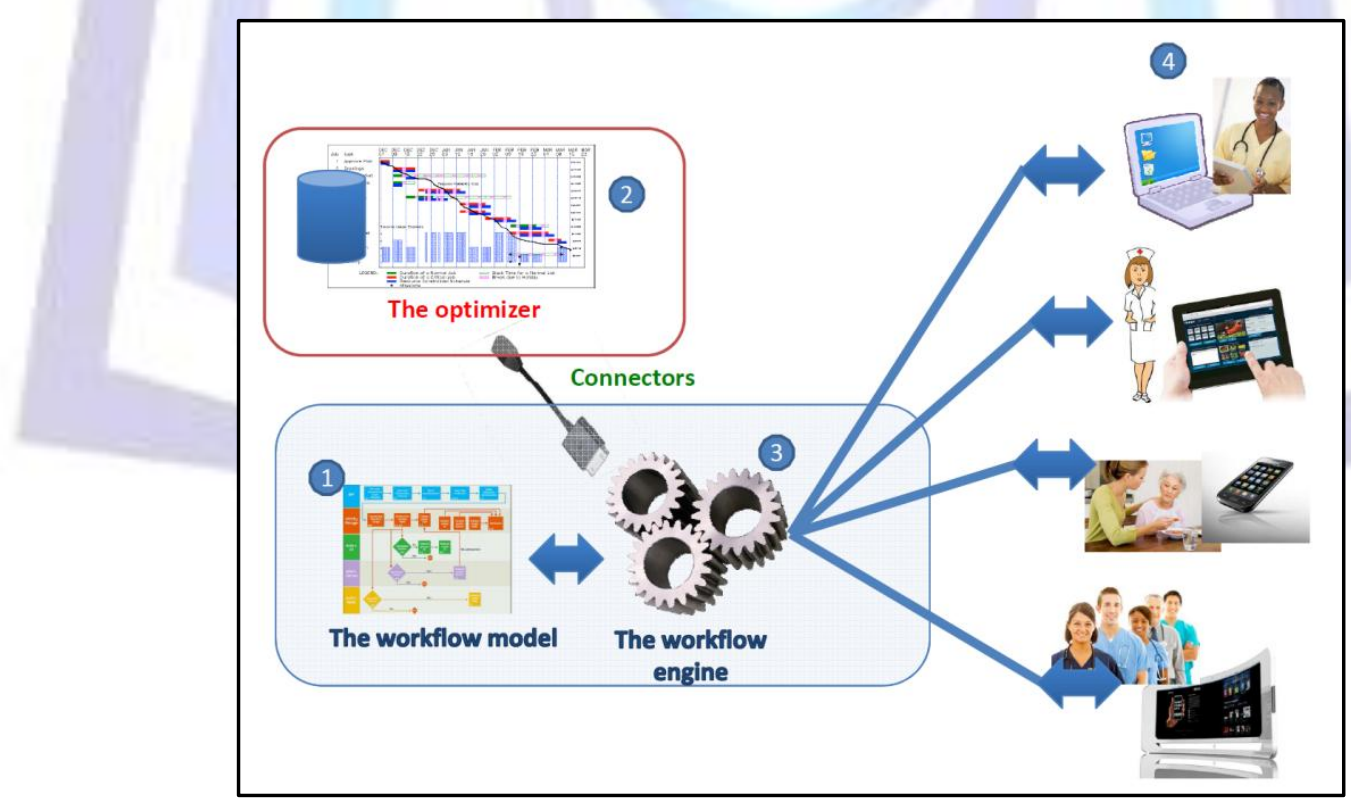

Fig 3: The OWS architecture

\section{The Modelling}

As justified in the previoussection, we adopted the workflow technique (based on the BPMN graphical language) and used the BonitaSoft software, to model the overall functioning of a nursing home. Before presenting the model, we explain the organization of a 'typical day' in a nursing home. 


\section{A typicalday Organisation}

A full day in a nursing home is divided into three Work Packages (WPs) (Fig 4). Each WP is defined by a set of tasks and a fixed deadline to not exceed.

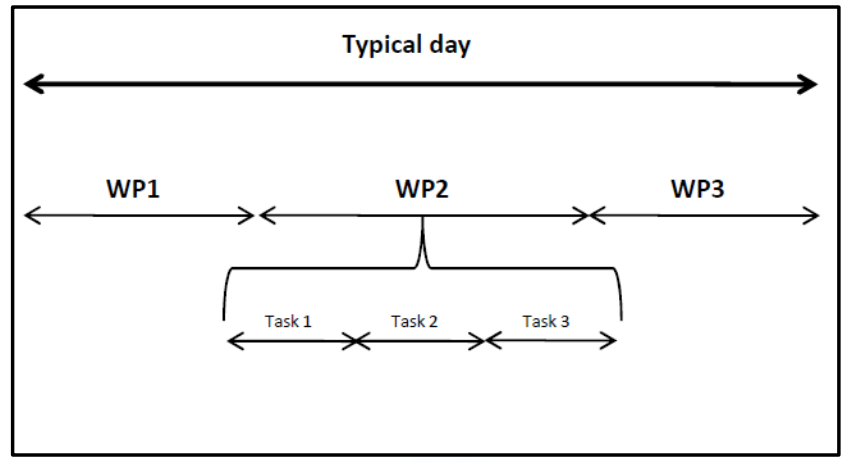

Fig 4: A typical day representation

We consider in this work that the tasks are not preemptible and the entire staff is continuously present during the accomplishment of WPs, that is to say, the breaks and changes of teams do not impact the execution of considered tasks.

These WPs are described as follows:

1. The first WP (WP1) consists of the wake-up and the breakfast with the drugs distribution;

2. The second WP (WP2) includes the toilet, potential care (medical and paramedical) and dressing;

3. The third WP (WP3) includes the dinner and at bedtime with drug distribution.

We chose to exclude certain measures of a typical day, as the transmission time and meetings, entertainment and taste. Indeed, these tasks are not likely to be optimized because they either do not directly concern residents (transmissions and meetings), or they do not involve scheduling problems (animation and taste).

\section{The global workflow model}

In order to model the organization of a nursing home, we have to represent separately its various units. To simplify the representation, we have shown only one unit (Fig 5). In future work, we will represent all units (three) and their interactions within the overall model.
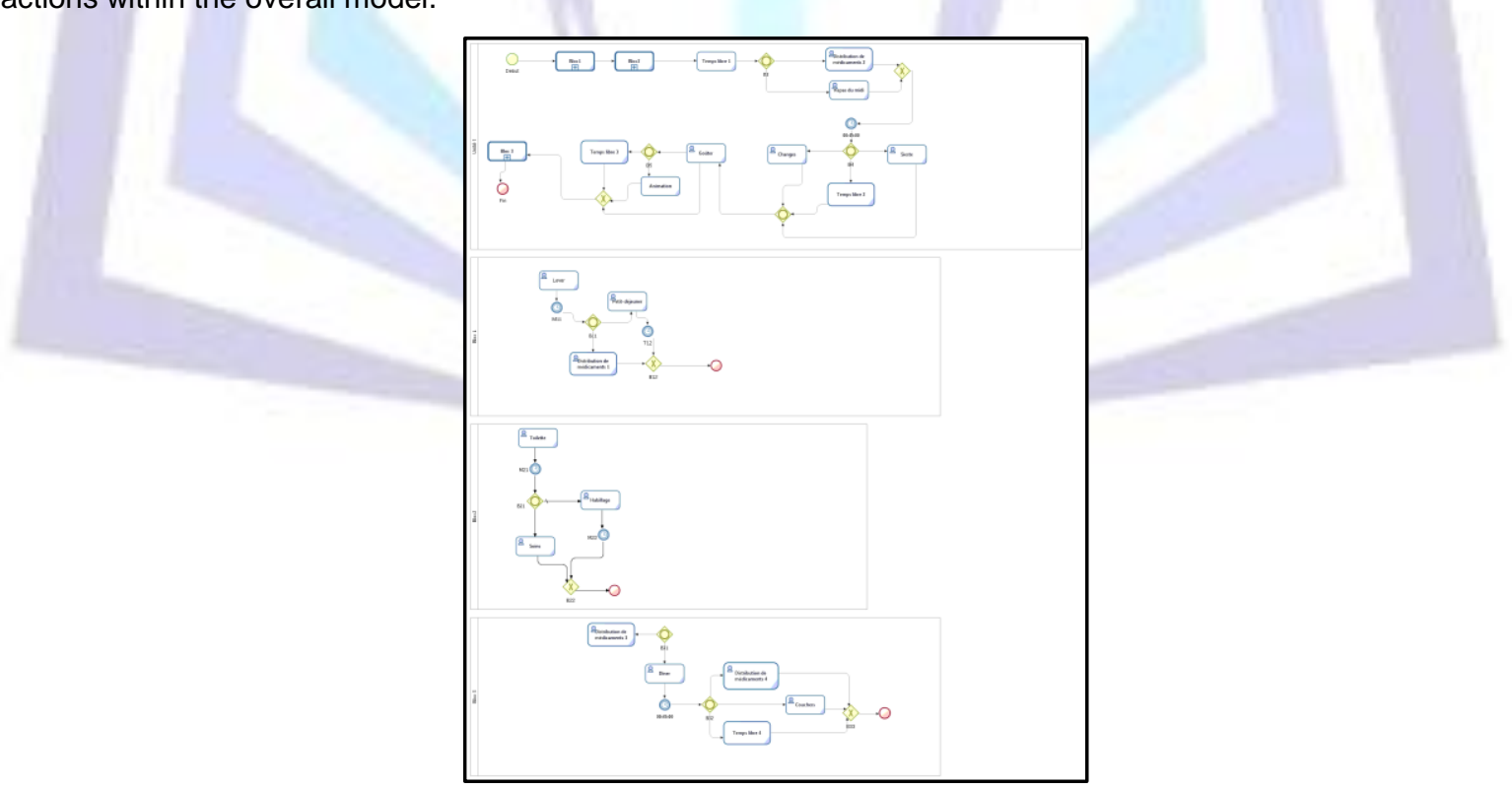

Fig 5: The global workflow model of the nursing home

Each unit is defined by a series of tasks divided into three WPs of a typical day, as defined in the previous section. Each WP is represented by a sub-process in the global model. This latter (Fig 5) is thus composed of a main process (corresponding to unit 1) and three sub-processes (corresponding to the three WPs).

A patient care is a mission related to a particular instance of the model. So each mission is a sequence of tasks to perform. This sequence is not always the same; it depends on the current instance of the process, for example the 
eventuality for a patient to have (or not) a treatment. All stages are connected by transitions (arrows), determining the order in which the process takes place. These transitions are the inputs or outputs of the gateways and are activated if the correspondent conditions are true. These conditional branches are linked to users' GUI for controlling the flow sequencing. The arrangement of the different instances represents the patients' scheduling; some of them are supported at the same time (parallel instances), and others not (sequential instances).

\section{Variablesdeclaration}

Once the different stages represented, we must define global variables (Fig 6) which will be used during the implementation of the model.

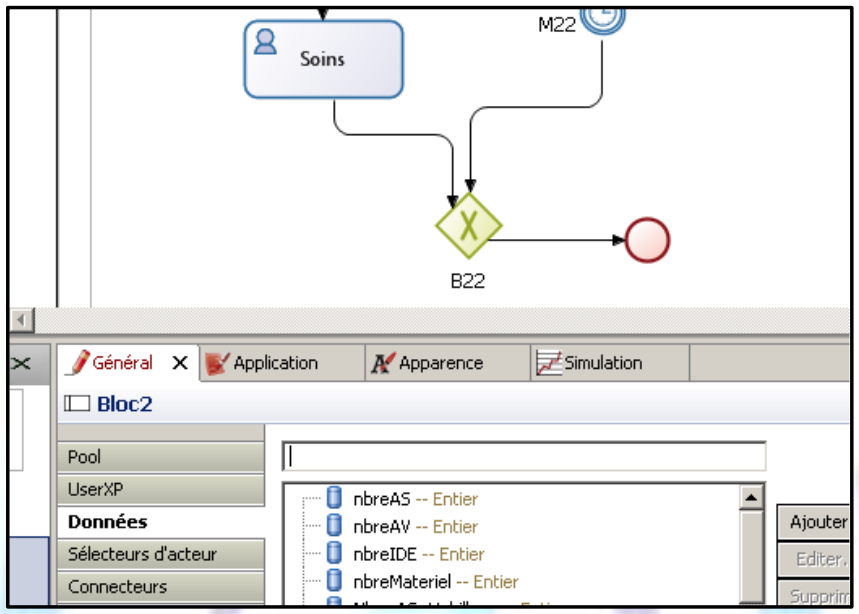

Fig 6: The variables' Settings

There are two types of global variables:

- The data resources. These variables allow the interaction (Fig 3) between the workflow model (1) and the optimizer (2) through the workflow engine (3). For example: $\boldsymbol{n b r e I D E}$ and $\boldsymbol{n b r e M a t e r i e /}$ variables correspond respectively to the number of nurses and equipments available in the establishment.

- $\quad$ The transition conditions. These variables enable the interaction (Fig 3) between the workflow model (1) and the communication devices (4) through the workflow engine (3).

It should be noted that when the running of the sub-processes (representing WPs) requires the access to the data of the global process (which is often the case), the system uses the 'Mapping' technique which allow an efficient sharing of data between global processes and its sub-processes.

\section{Actorsdeclaration}

This is to select, in terms of skills, the actors (resources) needed to achieve each task (Fig 7). So, each selected human resource will have on his IT support, the correspondent GUI of the running task.

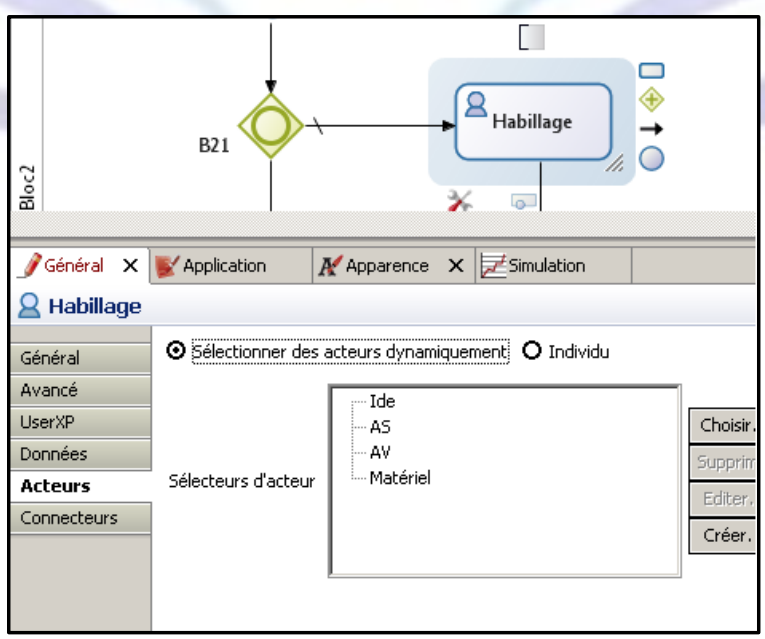

Fig 7: The skills parameters (Actors selection) 


\section{The unit workflow model}

The Fig 8 shows a model of a typical unit of the nursing home (Unit 1). This latter is represented by a global process triggered by a start event and closed by an end event. It includes all stages of the course of a typical day for a patient. This typical day is decomposed into a set of WPs each represented by a sub-process.

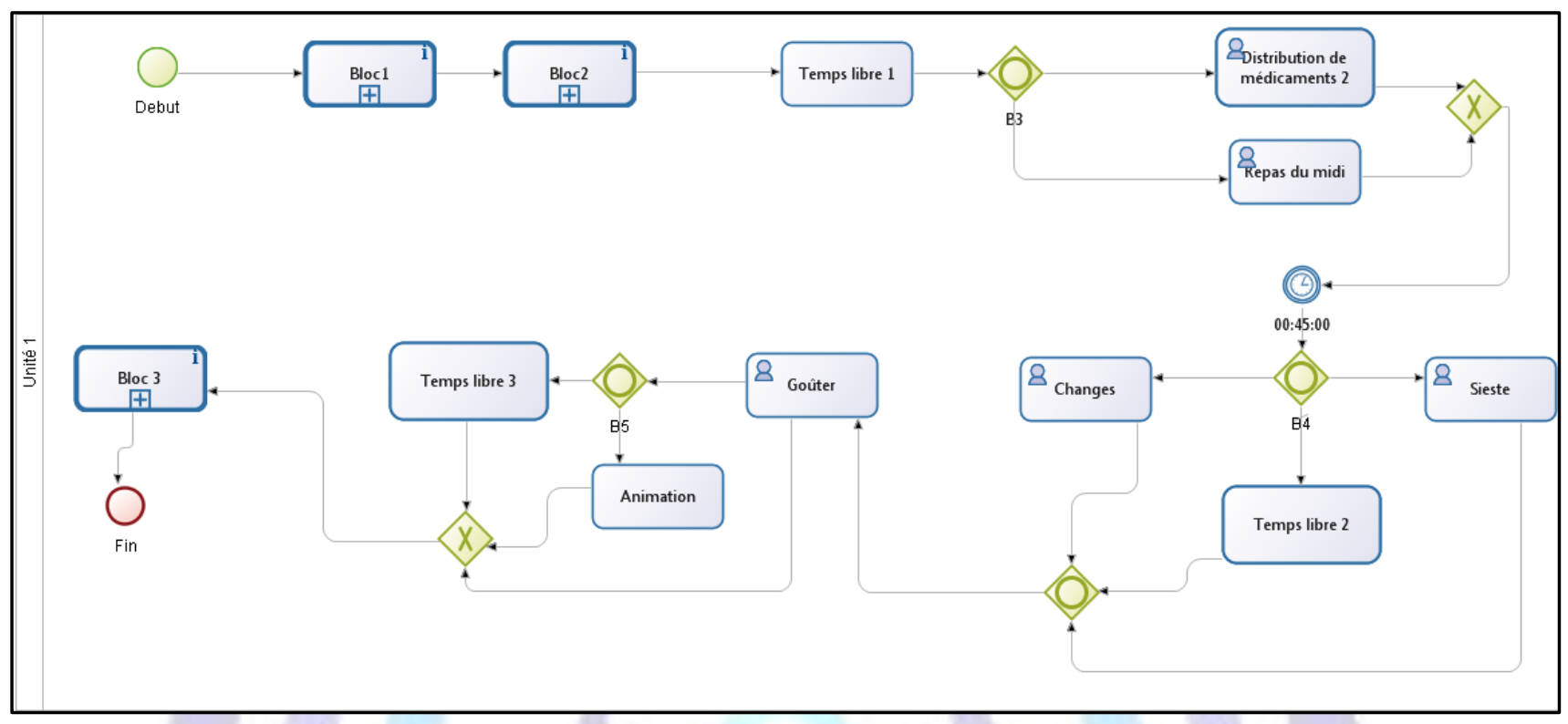

Fig 8:A care unit workflow model (unit 1)

\section{The Work package modelling}

We consider the sub-processes of the second work package (WP2) of the first unit (Unit 1). This latter is represented by theFig 9. All the steps of a sub-process are shown according the same principle as the global process discussed in the previous section: all stages are connected together by transitions and gateways to determine the order in which runs the modeled process. Gateways are used when some steps are not applicable to all residents. In this case, we use a special symbol (here an inclusive gateway) which allows the transition to one or more steps.

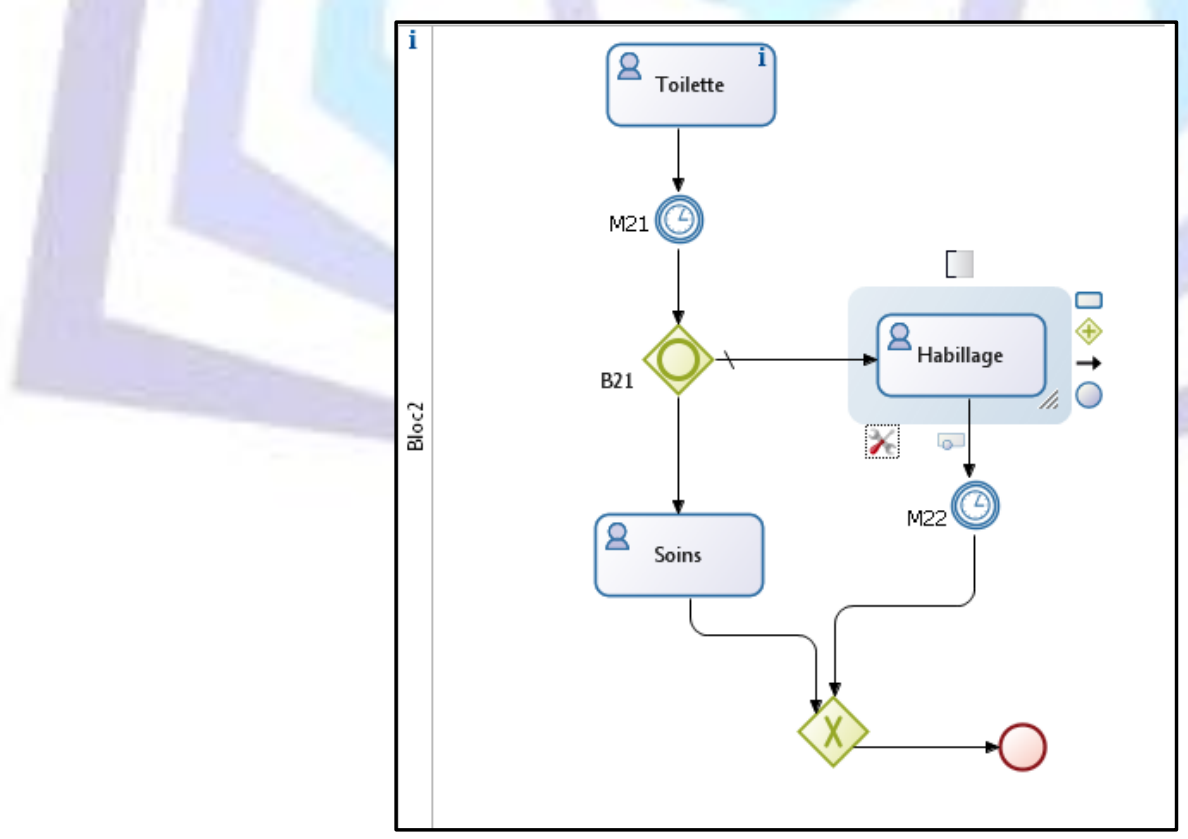

Fig 9: A workpackage workflow model (WP2)

As shown in the Fig 9, between the steps toilet (fr.' toilette '), care (fr. 'soins ') and dressing (fr. ' habillage '), we used an inclusive gateway which allows:

- $\quad$ The transition from the toilet step to the dressing step directly ;

- $\quad$ Or the transition from the toilet step to the dressing step while passing by the care step. 
Once the various steps represented, we have to declare the different variables and actors of sub-processes. This declaration is made in the same way that the global process.

For example, concerning the condition of transition from the toilet step to the carestep : the value assigned to the Boolean variable "Soins" identifies if the resident requires care (true value assigned) or not (false value assigned). If he requires, the model takes into account both the care and the dressing steps. In fact, this latter step is selected by default (striked out arrow).

\section{Time modelling: the timerevent item}

Some tasks require a shorter or longer assistance from the teams. A somewhat dependent resident may require only five minutes of assistance for his toilet, but he may take twenty minutes to continue to wash only. To represent this time condition, we use an intermediate timer event item in the form of a configurable timer, placed after the concerned step. We can see in the Fig 9that both the toilet and the dressing steps have a timer event.

\section{Actors-system interaction via graphical interfaces}

As mentioned earlier, we chose to generate graphical interfaces (as web forms). These interfaces allow human resources to interact with the application to set or get the right information at the right time for any patient care scenario. A scenario is thus a special instance of the workflow model that represents the care of a particular resident, with his constraints in terms of skills and care delays.

Through these interfaces, required data and the transition validation between steps (Fig 10) may be set in real time.

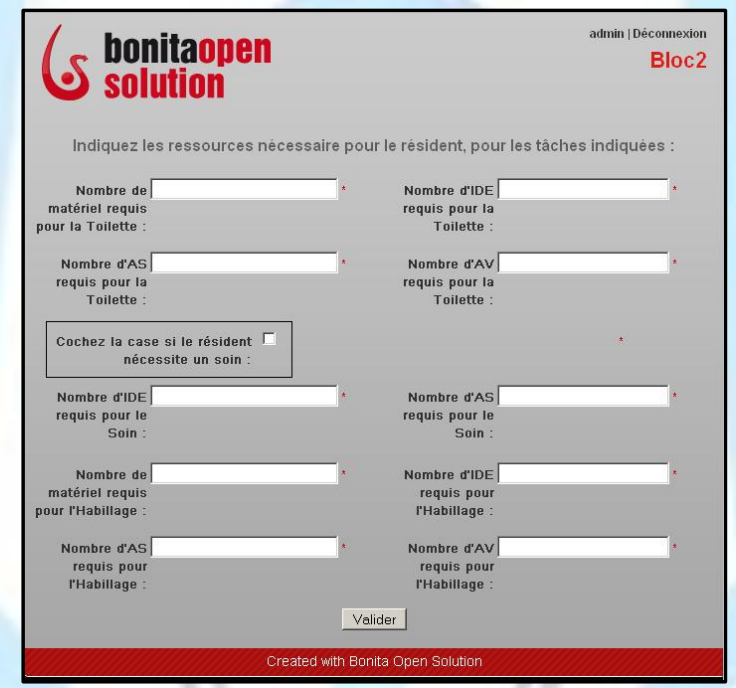

Fig 10: The requirement of the toilet step via the WP2 host interface (outlined)

However, the existing skills (e.g. total number of nurses, material resources, etc.) in the establishment should be mentioned from the beginning through the host application interface (Fig 11).

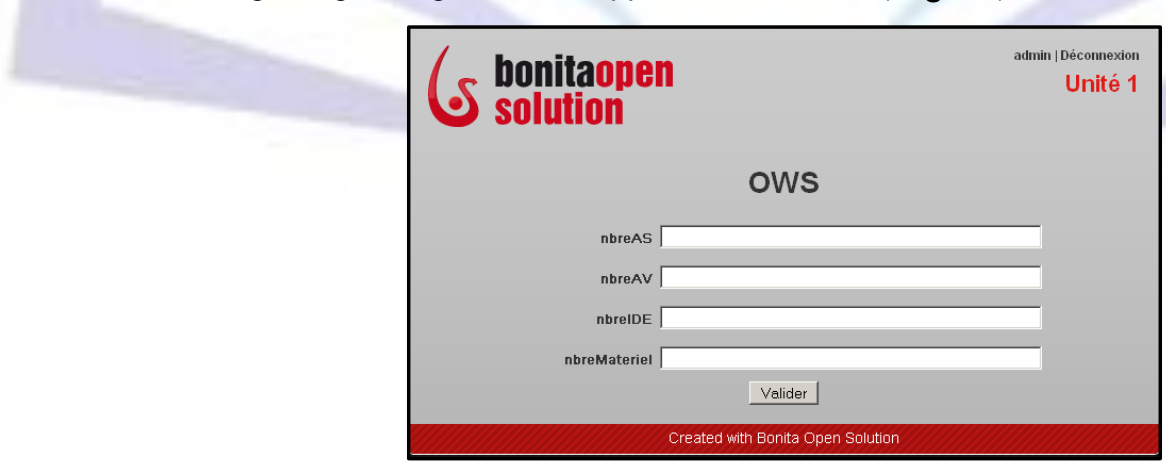

Fig 11: The OWS host application interface

The transitions between different stages are activated if the corresponding conditional expressions are true. These expressions use the previously process declared variables. Thus, the transition from the toilet step to the care step requires the assignment of the "true" value to the correspondent Boolean variable 'soins'. This is enabled via the GUI when the resident requires a care after the toilet step (Fig 10). It will be the same for all transitions where several steps may be involved. 
After modelling the global organization of a nursing home using workflow approach, we integrate to this model an optimization module. The idea is to find, in real time, the best possible assignment of resources available to perform the care tasks.

\section{The optimization}

\section{The generalprinciple}

The determination of the best organization of a nursing home goes through the organization of care the patient care. The task order is predefined (e.g. we cannot dress a patient without he being previously washed) and pseudo-static (e.g. a resident may sometimes require a care). This involves finding the best possible resources scheduling to perform these tasks.

For each task, the residents are accompanied according to their needs knowing that every patient's case is different. So each patient care requires special skills and equipments (we are talking about a patient lifts, allowing the manipulation of highly dependent residents).

These resources may be scarce in an institution. Thus, if the order in which staff take care residents is not correctly set, a considerable waiting time can be observed (e.g. waiting for a material in the case of picking up heavy). So, the order in which are cared the patients is a real challenge. We chose the genetic algorithm to solve this optimization problem. This choice was justified in the previous section.

\section{The problem formulation}

In this study, we consider the simultaneous care of a set of residents in a nursing home. For now, we focus on the optimization of the human and material resources allocation within a WP. But in future work, we will generalize our solution on an entire unit (including several WP), and then on all units of the establishment taking into account their potential interactions.

\section{The basic data}

- We consider the simultaneous care of $(R)$ residents.

- $\quad \operatorname{A~WP}_{r}(1 \leq r \leq R)$, is composed of $(J)$ tasks. So, we have: $\mathrm{WP}_{r}^{\mathrm{j}}(1 \leq \mathrm{j} \leq \mathrm{J})$ corresponds to the $\left(\mathrm{j}^{\text {th }}\right)$ task of the resident (r).

- For each task (j) of each resident (r), we have to specify a theoretical care time $\delta t_{r}^{j}$ (in minutes) according to the patient dependency. This theoretical care time is defined by professionals according to the establishment.

- As defined previously, when describing the decomposition in terms of WP of a typical day, the scheduling of a WP, for each resident ( $r$ ), must not exceed the fixed total duration that we denote by $\boldsymbol{t}_{\boldsymbol{f}}$.

\section{The resources and theirskills}

The human and material resources are the actors of the establishment which have the necessary capacities to intervene at different stages of the care process. There are 4 actors:

- IDE : The nurses,

AS/AMP: the healthcare assistants. In what follows, this resource will be denoted by: AS.

AV : the cares,

The Material.

We attribute for each resource a skill coefficient and we consider in this work that these coefficients are fixed. So, we have to identify, for each human task, all the resources that participate in its realization. For example, for the Bloc 2 (Fig 9 ), a care dispensation can only be achieved by an IDE or an AS, contrary to the toilet that is likely to be carried out by an IDE, an AS, an AV or a Material. Nevertheless, we have to distinguish between two types of resources: existent ones in the establishment (those available to us) and those that are needed to the patients' cares.

\section{- Existent resources}

Existent resources in the establishment must be known by the system: we consider the variables: $\overline{\mathrm{IDE}}, \overline{\mathrm{AS}}, \overline{\mathrm{AV}}$ et $\overline{\mathrm{Matériel}}$ which correspond respectively to cardinals of existent skills in the establishment on the considered period in terms of IDE, AS, AV (Table 2).

Table 2. The existent resources in the establishment

\begin{tabular}{|c|c|c|c|c|}
\cline { 2 - 5 } \multicolumn{1}{c|}{} & $\overline{\mathrm{AV}}$ & $\overline{\mathrm{AS}}$ & $\overline{\mathrm{IDE}}$ & $\overline{\text { Matériel }}$ \\
\hline Available skills (number) & 2 & 2 & 2 & 1 \\
\hline
\end{tabular}

We attribute for each resource a skill coefficient: 
So: $\theta_{\mathrm{IDE}}, \theta_{\mathrm{AS}}, \theta_{\mathrm{AV}}$ and $\theta_{\text {Material }}$ evaluate respectively the skill of the IDE, the AS, the AV and the material (Table 3 ). We consider in this work that these coefficients are fixed.

Table 3.Example of resources skills

\begin{tabular}{|c|c|c|c|c|}
\cline { 2 - 4 } \multicolumn{1}{c|}{} & $\theta_{\mathrm{AV}}$ & $\theta_{\mathrm{AS}}$ & $\theta_{\mathrm{IDE}}$ & $\theta_{\text {Material }}$ \\
\hline Skills' coefficients & 0.1 & 1 & 100 & 1000 \\
\hline
\end{tabular}

At a given time $(\boldsymbol{t})$, the total existent skill of all the material and human resources is calculated respectively by the Equation 1 and the Equation 2 below. The sum of existing skills is calculated by the Equation 3.

\section{Equation 1. The total skill of existent material resources}

$\overline{\theta \mathrm{m}}=\theta_{\text {Mat ériel }} \times \overline{\text { Matériel }}$

\section{Equation 2. The total skill of existent human resources}

$\overline{\theta p}=\theta_{A V} \times \overline{A V}+\theta_{A S} \times \overline{A S}+\theta_{I D E} \times \overline{I D E}$

\section{Equation 3. The total existent skills}

$\bar{\theta}=\overline{\theta m}+\overline{\theta p}$

If we consider the existing resources mentioned in the Table 2 and their respective skills coefficients mentioned in the Table 3then the total existing skills in the establishment is equal to 1000 for the material and to 102,2 to the human resources (Table 4 ).

Table 4.Example of total skill computation

\begin{tabular}{|c|c|}
\cline { 2 - 2 } \multicolumn{1}{c|}{} & Total compétences \\
\hline$\theta_{\text {Matériel }} \times \overline{\text { Matériel }}$ & 1000 \\
\hline$\theta_{A V} \times \overline{A V}+\theta_{A S} \times \overline{A S}+\theta_{I D E} \times \overline{I D E}$ & 102,2 \\
\hline
\end{tabular}

\section{- Needed resources}

At a given time ( $\mathbf{t}$ ), it is necessary to identify theresources to be allocatedtoeach resident ( $\mathbf{r}$ ) for each task (j). We therefore considerthe following variables: $\operatorname{IDE}_{\mathrm{r}}^{\mathrm{j}}, \mathrm{AS}_{\mathrm{r}}^{\mathrm{j}}, \mathrm{AV}_{\mathrm{r}}^{\mathrm{j}}$ and Material $\mathrm{l}_{\mathrm{r}}^{\mathrm{j}}$ which correspond to the number of IDE, AS, AV and Materials to be assigned to the resident ( $r$ ) for the task (j).

At a given time $(\boldsymbol{t})$, the total skills to be assigned to the resident $(\boldsymbol{r})$ for his care task $(\mathbf{j})$, is computed respectively by the Equation 4 for the human resources and by the Equation 5 for the material resources. The sum is computed by the Equation 6.

\section{Equation 4. Total needed human skills to be assigned to the resident ( $r$ ) for his task (j)}

$$
\theta p_{r}^{j}=\theta_{I D E} \times I D E_{r}^{j}+\theta_{A S} \times A S_{r}^{j}+\theta_{A V} \times A V_{r}^{j}
$$

\section{Equation 5. Total needed material skills to be assigned to the resident ( $r$ ) for his task (j)}

$$
\theta \mathrm{m}_{\mathrm{r}}^{\mathrm{j}}=\theta_{\text {Material }} \times \text { Material }_{\mathrm{r}}^{\mathrm{j}}
$$

Equation 6. Total skills to be assigned to the resident ( $r$ ) for his task (j)

$$
\theta_{r}^{j}=\theta p_{r}^{j}+\theta m_{r}^{j}
$$

At a given time $(\boldsymbol{t})$, it is necessary to identify the total needed human and material skills for all the care tasks and for all the residents (Equation and Equation 8). The sum $(\theta)$ is computed by the Equation 9. These data must be entered into the system as shown in the Table 5 for all the residents. This table also informs the theoretical time estimated for each task.

Table 5. Example of WP2data concerning the resident $1(r=1)$

\begin{tabular}{|c|c|c|c|c|c|c|}
\cline { 2 - 7 } \multicolumn{1}{c|}{} & \multicolumn{2}{c|}{$T_{\mathbf{1}}=$ Toilette } & \multicolumn{2}{c|}{$T_{2}=$ Soins } & \multicolumn{2}{c|}{$T_{3}=$ Habillage } \\
\cline { 2 - 7 } \multicolumn{1}{c|}{} & $\boldsymbol{\theta}_{r}^{\mathbf{1}}$ & $\delta t_{r}^{\mathbf{1}}$ & $\boldsymbol{\theta}_{r}^{\mathbf{2}}$ & $\delta t_{r}^{\mathbf{2}}$ & $\theta_{r}^{\mathbf{3}}$ & $\delta t_{r}^{\mathbf{3}}$ \\
\hline Résident 1 & 0 & 30 & 100 & 7 & 1,1 & 10 \\
\hline
\end{tabular}

\section{Equation 7. The human total needed skills}

$$
\theta p=\sum_{r=1}^{R} \sum_{j=1}^{J} x_{j, r} \cdot \theta p_{r}^{j}
$$




\section{Equation 8. The material total needed skills}

$$
\theta m=\sum_{r=1}^{R} \sum_{j=1}^{J} x_{j, r} . \theta m_{r}^{j}
$$

$x_{j, r}$ is a boolean variable as follows :

$x_{j, r}=1$ if the task (j) belongs to the care process of the resident $(r)$ and $x_{j, r}=0$ otherwise.

\section{Equation 9. The total needed skills (human and material)}

$$
\theta=\theta m+\theta p
$$

\section{Decision variables}

The idea is to act on the start and end times of tasks and WPs $T_{r}=\left[T_{r}^{1}, \ldots, T_{r}^{J}\right]$ for each resident. Therefore, we identified the following Decision Variables (DV) for each resident $(r)(1 \leq r \leq R)$ :

- $t d_{r}$ : The start time of the WP $\left(\mathrm{T}_{\mathrm{r}}\right)$ concerning the resident $(\mathrm{r})$.

- $\quad t f_{r}^{j}$ : The end time of the task (j) concerning the resident $(r)$ with: $t f_{r}^{j}=t d_{r}+\sum_{k=1}^{j} \delta t_{r}^{k}$.

- $\quad t f_{r}$ : The end time of the WP $\left(\mathrm{T}_{\mathrm{r}}\right)$ concerning the resident $(\mathrm{r})$ with $: t f_{r}=t d_{r}+\sum_{j=1}^{J} \delta t_{r}^{j}$.

The DSS must compute the optimal values for these DV for each resident. This calculation must be done taking into account the time constraints, those related to resources and those induced by the residents themselves.

\section{The constraints}

In our problem, each resident induces constraints for the execution of each task. Some residents want or need to be taken care first and others last, some refuse a support, some require a heavier care than others depending on their addiction, etc. This implies constraints on mobilized resources: Depending on the state and the willingness of residents, and also on their wishes and needs. These constraints must be taken into account respecting delays. We must therefore distinguish 3 types of constraints: time constraint, priority constraints and resources constraints.

\section{- $\quad$ Time constraints}

Each WP, starting from the date $T_{0}=0$, must not exceedthe time $t_{f}$ in order tonotshift theotherWPof the day. For example, theWP $\mathrm{P}_{2}$ (toilet-care-dressing) cannot start before theresident isup andtook hisbreakfast(untilabout9:30) andafter he wentto eat(to about12h00).So it has atimelimit of 150 minutes $\left(t_{f}=150 \mathrm{mn}\right)$.

This constrainthas to be takeninto account whensolving the problem. It results inthe fact thatthe start timeof theWPfor each residentmust beless than a start timelimit. The Equation 10 allows to compute, for each resident $(r)$, the later time limit (tlim $)_{r}$ of the WP $\left(T_{r}\right)$ :

\section{Equation 10}

$$
\operatorname{tlim}_{r}=t_{f}-\sum_{j=1}^{J} \delta t_{r}^{j}
$$

We remind you that: $\left(\mathrm{t}_{\mathrm{f}}\right)$ corresponds to the time limit to realize a WP and that $\left(\delta \mathrm{t}_{\mathrm{r}}^{\mathrm{j}}\right)$ corresponds to the theoretical care time of a resident $(r)$ for the task $(j)$. The time constraint is then expressed by the Equation 11 below: the start date of the WP $\left(t d_{r}\right)$ of the resident $(r)$ must not exceed the latest start limit time $\left(\operatorname{tlim}_{r}\right)$ :

Equation 11

$$
\operatorname{td}_{\mathrm{r}} \leq \operatorname{tlim}_{\mathrm{r}}, \forall \mathrm{r}(1 \leq \mathrm{r} \leq \mathrm{R})
$$

We can then deduce the Equation 12 : the end time $\left(\mathrm{tf}_{\mathrm{r}}\right)$ of the WP $\left(\mathrm{T}_{\mathrm{r}}\right)$ of the resident $(\mathrm{r})$ must not exceed the deadline $\left(\mathrm{t}_{\mathrm{f}}\right)$.

\section{Equation 12}

$$
\mathrm{tf}_{\mathrm{r}} \leq \mathrm{t}_{\mathrm{f}}, \forall \mathrm{r}
$$

\section{- $\quad$ The residents' priorities}

\section{As soon as possible}

In order to take care of the priority resident, then, at a given time $(\mathrm{t})$, his maximum care timehas to beless than the minimumcare time of the other residents.

Let $\left(r^{*}\right),\left(1 \leq r^{*} \leq R\right)$ represents a priority resident. Then, the constraint expressed by the Equation 13 below must be respected: 


\section{Equation 13}

\section{As late as possible}

If a residentwants(orshould) betaken careas late as possible, then, at a given time ( $\mathrm{t}$ ), his minimum care time has to be greater than themaximumcare time of theother residents.

Let $\left(r^{* *}\right),\left(1 \leq r^{* *} \leq R\right)$ represents a residentwho wants to(orshould) betaken careafter the. Then, the constraint expressed by the Equation 14 below has to be respected:

Equation 14

$$
\begin{aligned}
& \max _{1 \leq r^{*} \leq R}\left(t d_{r^{*}}\right)<\min _{1 \leq r \leq R}\left(t d_{r}\right) \\
& \text { with } r \neq r^{*} \forall r, r^{*}\left(1 \leq \mathrm{r}, \mathrm{r}^{*} \leq \mathrm{R}\right)
\end{aligned}
$$

$$
\min _{1 \leq r^{* *} \leq R}\left(t d_{r^{* *}}\right)>\max _{1 \leq r \leq R}\left(t d_{r}\right) \text { with } r \neq r^{* *} \forall r, r^{* *}\left(1 \leq \mathrm{r}, \mathrm{r}^{*} \leq \mathrm{R}\right)
$$

\section{Resources constraints}

We already presented above two kinds of resources: existent resources in the establishment and needed resources for care at a given time (t). Obviously, used resources must not exceed existent resources at a given time $(\boldsymbol{t})$. This expressed by the Equation 15 below for the human resources and by the Equation 16 for the material resources.

\section{Equation 15. Human resources constraints}

\section{Equation 16. Material resources constarints}

$$
\begin{gathered}
\theta p \leq \overline{\theta p} \\
\theta m \leq \overline{\theta m}
\end{gathered}
$$

\section{The objective function}

We can optimize the patient care planning in different ways. Intuitively, we have to minimize the time care. However, in this study we act in the medico-social field and not in the industrial field. It is therefore important to consider the human aspect. Thus, we have to reduce the workload of the staff. The idea is to free up human resources allowing the staff to spend more time with the residents. Furthermore, this technique will strengthen the robustness of the system which will be able to handle the disturbances such as denial of care or emergencies.

\section{- $\quad$ The time care}

We can optimize trying to gain a maximum amount of time starting each WP as soon as possible to complete the care as soon as possible. For this, we must minimize the sum of the start times of each WP for all residents (Equation 17).

\section{Equation 17}

$$
\forall \mathrm{t}, \mathrm{f}_{\text {temps }}=\sum_{\mathrm{r}=1}^{\mathrm{R}} \mathrm{td}_{\mathrm{r}}
$$

\section{- $\quad$ The workload}

The goal is to minimize the staff workload (Equation 18).

Equation 18

$$
\forall \mathrm{t}, \mathrm{f}_{\text {charge }}=\theta p
$$

We recall that $(\theta p)$ is given by the Table 5 . Example of WP2data concerning the resident $1(r=1)$

\begin{tabular}{|c|c|c|c|c|c|c|}
\cline { 2 - 7 } \multicolumn{1}{c|}{} & \multicolumn{2}{c|}{$T_{\mathbf{1}}=$ Toilette } & \multicolumn{2}{c|}{$T_{2}=$ Soins } & \multicolumn{2}{c|}{$T_{3}=$ Habillage } \\
\cline { 2 - 7 } \multicolumn{1}{c|}{} & $\boldsymbol{\theta}_{r}^{\mathbf{1}}$ & $\delta \boldsymbol{t}_{r}^{\mathbf{1}}$ & $\boldsymbol{\theta}_{r}^{\mathbf{2}}$ & $\delta \boldsymbol{t}_{r}^{\mathbf{2}}$ & $\boldsymbol{\theta}_{r}^{\mathbf{3}}$ & $\delta \boldsymbol{t}_{r}^{\mathbf{3}}$ \\
\hline Résident 1 & 0 & 30 & 100 & 7 & 1,1 & 10 \\
\hline
\end{tabular}

\section{Equation 7.}

\section{- The aggregative approach}

Although both presented objectives are contradictory, the developed model allows taking into account each of them with a blending function using a weighting coefficient $\alpha \in[0,1])$. So, according to the assigned value of $(\alpha)$, we aim to minimize the overall patient care time and the staff workload. For the extreme cases, when we want to minimize the time care without considering the workload, we have simply to assign to the coefficient ( $\alpha$ ) the " 0 " value. Inversely, in order to minimize workload without considering the time care, we have simply to assign to the coefficient ( $\alpha$ ) the " 1 " value. So, we consider the objective function expressed by the Equation 19 below to be minimized. 


\section{Equation 19}

\section{DISCUSSIONS}

To discuss the effectiveness of the proposed solution, we choose to compare the organization of an existing nursing home with and without the use of our tool. To do this, we must firstly provide the required data to establish the planning of material and human resources for the care:

1. The basic data: the theoretical care time for each task (j) of each resident $(r): \delta t_{r}^{j}$ and the fixed total duration ( $\left.\mathrm{t}_{\mathrm{f}}\right)$ to not exceed for each WP.

2. The existent resources in the establishment and the needed resources for each task of each resident.

\section{The establishment information}

\section{Background}

The concerned nursing home started its activities in 1949. Its last tripartite agreement dates back to 2007. It is composed of three units on three separate floors. The main characteristics of this establishment are presented in Table 6; the services' distribution is presented in Table 7and that of residents per unit inTable 8.

Table 6. The nursing home characteristics

\begin{tabular}{|c|c|}
\hline ITEM & RESPONSE \\
\hline The establishment capacity (number of beds) & 60 \\
\hline The temporary lodgingcapacity & 0 \\
\hline The day capacity & no alzheimer units \\
\hline The alzheimerunit capacity & 650 \\
\hline Last evaluated GMP & 108 \\
\hline Last evaluated PMP & 87.3 \\
\hline The average age of residents & \\
\hline
\end{tabular}

Table 7. Services' distribution in the nursing home

\begin{tabular}{|c|c|c|}
\hline SERVICE & Authorized full time equivalent & Real full time equivalent \\
\hline Directors (Secretariat) & 3 & 3 \\
\hline Coordinator physician & 0.46 & 0.46 \\
\hline IDEC & 0.75 & 3 \\
\hline IDE & 3 & 13.5 \\
\hline AS & 13.5 & 9 \\
\hline AV & 9 & 28.96 \\
\hline TOTAL & 28.96 & \\
\hline
\end{tabular}

Table 8.Residents' distribution per unit

\begin{tabular}{|c|c|}
\hline UNIT & Number of residents \\
\hline 1 & 20 \\
\hline 2 & 20 \\
\hline 3 & 20 \\
\hline
\end{tabular}

We focus in this study on a single unit: the unit 1, and on a single WP: the WP2. The principle is the same for all other units and WPs of the establishment. But in future works, we will study the interaction between the different WPs through different units. 
It is interesting to start our project with the WP2 because it is composed of various tasks, requiring different skills (material, AS or AV for toilet and dressing, IDE for the care), and not related necessarily all residents (the example of the care).

\section{Data concerning the WP2}

In this WP, the distribution of staff on a typical day is mentioned in Table 9and the workload (care time and resources) required for each resident by task inTable 10. For the workload, the names of the residents are mentioned according to their room number. But they are fictional residents. However, needed care time and needed resources are identified by professionals working in the nursing home.

Table 9. Distribution of staff on a typical day for the unit 1

\begin{tabular}{|c|c|}
\hline WP & Number of residents \\
\hline WP2 & IDE $=1$ \\
toilet- care-dressing & $\mathrm{AS} / \mathrm{AMP}=5$ \\
& $\mathrm{AV}=4$ \\
& Material $=1$
\end{tabular}

Table 10.Needed care time and resources of each task for each resident for the WP2

\begin{tabular}{|l|c|c|c|c|c|c||}
\hline \multirow{2}{*}{ RESIDENTS } & \multicolumn{2}{|c|}{ TOILETTE } & \multicolumn{2}{c|}{ SOINS } & \multicolumn{2}{c||}{ HABILLGE } \\
\cline { 2 - 7 } & Compétence & Temps & Compétence & Temps & Compétence & Temps \\
\hline Résident 1 & 0 & 20 & 1 & 5 & 0 & 10 \\
Résident 2 & 0 & 20 & 0 & 0 & 0 & 10 \\
Résident 3 & 0 & 20 & 100 & 10 & 0 & 10 \\
Résident 4 & 1 & 5 & 0 & 0 & 1 & 5 \\
Résident 5 & 1 & 5 & 100 & 5 & 1 & 5 \\
Résident 6 & 1,1 & 10 & 0 & 0 & 1,1 & 10 \\
Résident 7 & 1 & 20 & 100 & 5 & 1 & 10 \\
Résident 8 & 1 & 25 & 0 & 0 & 1 & 10 \\
Résident 9 & 2 & 20 & 100 & 10 & 1001,1 & 10 \\
Résident 10 & 1,1 & 20 & 101 & 15 & 101 & 10 \\
Résident 11 & 1,1 & 10 & 0 & 0 & 1,1 & 10 \\
Résident 12 & 1,1 & 10 & 100 & 10 & 1,1 & 10 \\
Résident 13 & 1,1 & 10 & 1 & 5 & 1,1 & 10 \\
Résident 14 & 0 & 20 & 1 & 5 & 0 & 10 \\
Résident 15 & 1,1 & 10 & 0 & 0 & 1,1 & 10 \\
Résident 16 & 0 & 20 & 1 & 5 & 0 & 10 \\
Résident 17 & 1,1 & 10 & 100 & 10 & 1,1 & 10 \\
Résident 18 & 2 & 20 & 100 & 5 & 1001,1 & 10 \\
Résident 19 & 0 & 20 & 100 & 5 & 0 & 10 \\
Résident 20 & 1 & 5 & 0 & 0 & 1 & 5 \\
\hline \hline
\end{tabular}

\section{The consideredconstraints}

We set the following constraints:

- The time Constraint: $t_{f}=150 \mathrm{mn}$. This means that the optimal solution to find must not exceed the maximum period of 150 minutes for the care of the 20 residents with the available resources.

- The priority constraint: the residents $1,2,11$ and 12 have priority. Thereforetheyshouldbetaken care of first.

\section{The planning without the OWS}

The Table 11 is an example of resources' planning that could adopt the establishment trying to respect the constraints mentioned above. This planning was set up based on the staff experience and organizational strategies. However, a problem arises: the regular overflow of the care time for the concerned WP (Toilet -Care-Dressing).

Table 11. The result of the planning without the proposed tool (max $235 \mathrm{~min}$ )

\begin{tabular}{|c|c|c|c|c|c|c|c|c|c|c|c|c|c|c|c|c|c|c|c|c|}
\hline \multicolumn{21}{|c|}{ Oryntution en plist } \\
\hline $\begin{array}{l}\text { Grea de prise an thyte } \\
\text { de rethen! }\end{array}$ & 1 & 2 & 3 & 4 & 5 & 6 & 7 & 8 & 9 & 10 & 11 & 12 & 13 & 14 & 15 & 16 & II & 18 & 19 & 20 \\
\hline identification du rthidert & E1 & $\overline{\mathbf{B}}$ & B.II & MII & 1720 & Bis & Bis & Eid & Eil? & B19 & Bit & 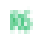 & M18 & 150 & $\overline{\mathbf{B}} \mathbf{3}$ & 6 & WI & 813 & is & E16 \\
\hline $\begin{array}{l}\text { Date de dtbut de pise en } \\
\text { chare }\end{array}$ & 0 & 0 & 0 & 0 & s & 10 & 20 & 31 & H & 50 & 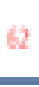 & 67 & $\beta$ & 4 & 10 & 117 & 145 & 15 & 17 & 200 \\
\hline $\begin{array}{l}\text { Date de HN de prise on } \\
\text { thuge }\end{array}$ & w & M & 20 & $D$ & 20 & 42 & is & 6 & 4 & 5 & $n$ & 8 & 114 & 129 & 14 & 197 & 10 & 190 & 192 & 235 \\
\hline
\end{tabular}


The Fig 12shows the usual consumption of the resources in the usual planning (we recall that: $\theta \mathrm{AV}=0.1 ; \theta \mathrm{AS}=1 ; \theta \mathrm{IDE}$ $=100$; $\theta$ Material $=1000)$. We observe that the consumption of resources has been respected but the care time has been exceeded.

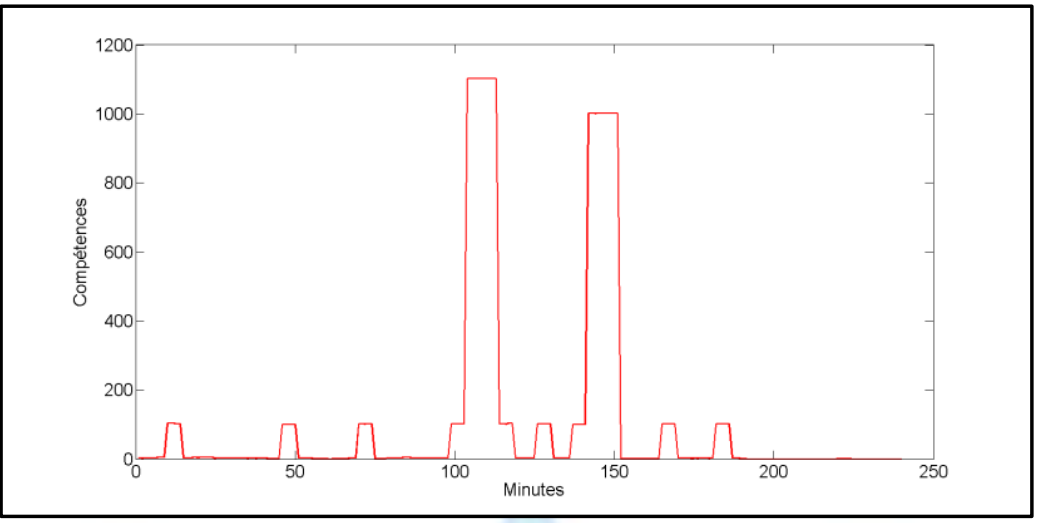

Fig 12: Resources consumption without the OWS tool

\section{The optimized planning with the OWS}

\section{Data and parameters}

We chose to set the weighting coefficient to $0.5(\alpha=0.5)$ to have a balanced solution between minimizing the overall time for the care of patients and the distribution of the staff workload.

The Fig 13represents the interface of the optimization module of our OWS tool. In the upper left corner of the figure, we can see the data corresponding to the different available resources in the establishment in terms of numbers and skills. We can see the needs of time and resources for each resident at the bottom left of the same figure. The part dedicated to the optimization, which will generate and display the optimal solution is on the right.

We recall here that we adopted a genetic algorithm for the optimization stage. In order to activate the program, we have set a number of parameters (mutation probability, number of iterations, etc.) that we varied so that the algorithm determines the best solution according to the objective function (Equation 19).

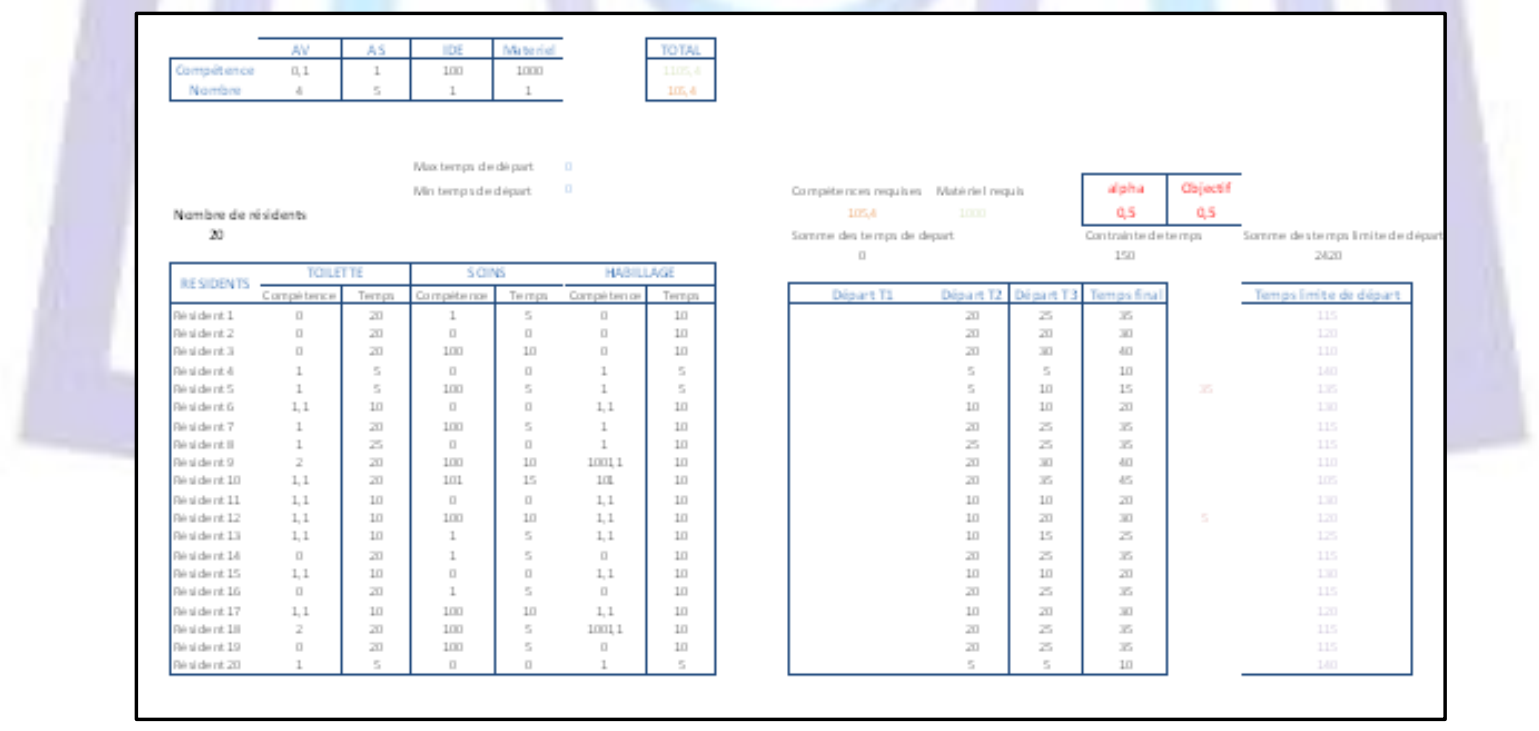

Fig 13: The optimisation module of the OWS tool

\section{The result of the optimization stage}

Based on the same initial parameters as the usual planning but using this time our tool, we obtain an optimized planning.The Fig 14represents the resources' consumption according to this optimization. We note that with the same existent resources for the usual planning, we get a better solution. This approach respects the considered initial constraints, including the priority of some residents and the total time which should not exceeds $150 \mathrm{mn}$ (tf $=150 \mathrm{~min}$ ). 
Table 12. The result of the planning with the proposed tool (max $143 \mathrm{~min}$ )

\begin{tabular}{|l|c|c|c|c|c|c|c|c|c|c|c|c|c|c|c|c|c|c|c|c|}
\hline $\begin{array}{l}\text { Ordice de prise en charge } \\
\text { du résident }\end{array}$ & $\mathbf{1}$ & $\mathbf{2}$ & $\mathbf{3}$ & $\mathbf{4}$ & $\mathbf{5}$ & $\mathbf{6}$ & $\mathbf{7}$ & $\mathbf{8}$ & $\mathbf{9}$ & $\mathbf{1 0}$ & $\mathbf{1 1}$ & $\mathbf{1 2}$ & $\mathbf{1 3}$ & $\mathbf{1 4}$ & $\mathbf{1 5}$ & $\mathbf{1 6}$ & $\mathbf{1 7}$ & $\mathbf{1 8}$ & $\mathbf{1 9}$ & $\mathbf{2 0}$ \\
\hline identification du resident & R1 & R2 & R11 & R12 & R15 & R16 & R14 & R17 & R1s & Rs & R19 & R3 & R5 & R13 & R7 & RS & R10 & R6 & R4 & R20 \\
\hline $\begin{array}{l}\text { Date de début de prise en } \\
\text { charge }\end{array}$ & 0 & 0 & 0 & 0 & 6 & 17 & 20 & 22 & 31 & 54 & 62 & 67 & 79 & 81 & 98 & 102 & 106 & 124 & 132 & 133 \\
\hline $\begin{array}{l}\text { Date de FiN de prise en } \\
\text { charge }\end{array}$ & 35 & 30 & 20 & 30 & 26 & 52 & 55 & 52 & 66 & 89 & 97 & 107 & 119 & 106 & 133 & 117 & 151 & 144 & 142 & 143 \\
\hline
\end{tabular}

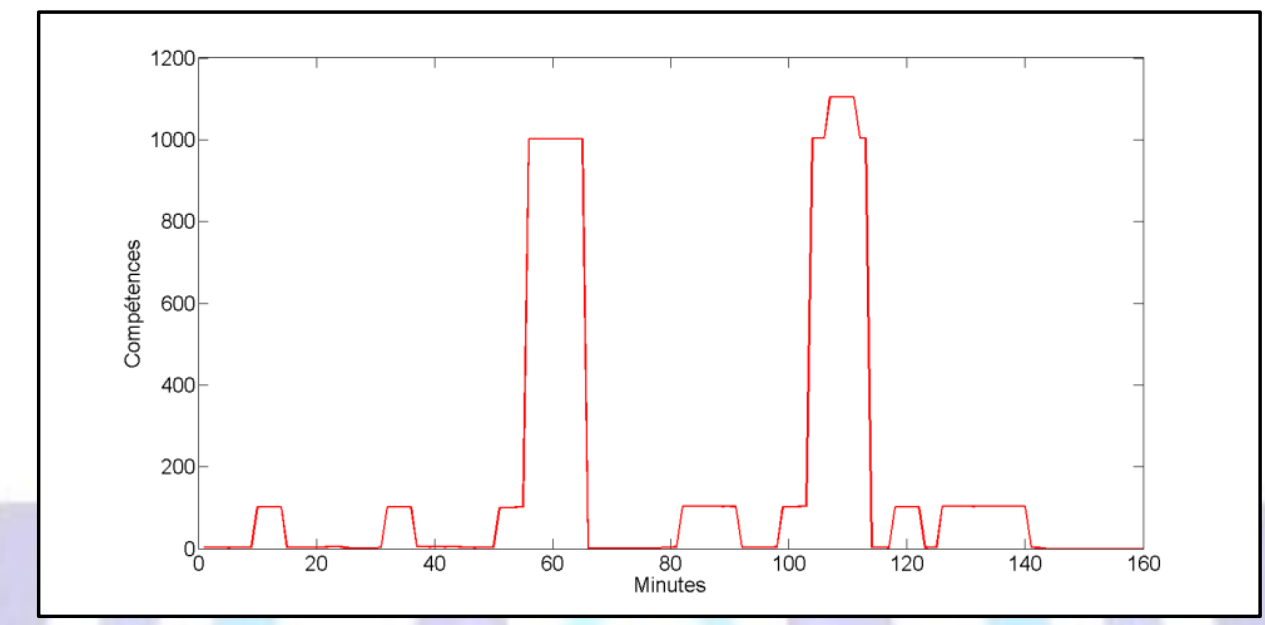

Fig 14: Resources consumption with the OWS tool

\section{CONCLUSION AND PROSPECTS}

Thanks to innovative approaches and logistic tools (workflow modeling and multi-objective optimization), we propose in this paper a Decision Support System (DSS), that we called OWS. The objective of this system is to optimize the organization of care for residents in a nursing home. Based on the same initial parameters (eg. available resources), we have proved the effectiveness of our tool by comparing a usual planning (without the OWS tool) and an optimized planning (with woop) in the same establishment. The usual planning is set up based on the experience and organizational strategies of the staff while the optimized planning is generated using our proposed system. This latter is composed of two complementary module: 1) the Workflow component that represents the organization of the different units of the establishment with their different work packages, this represents the global model of the organization of the nursing home and 2 ) the optimization component, which aims to optimize efficiently the assignment of the human and material resources for the care of residents.

Within the Workflow component, the DSS is connected to an integrated database to store temporarily all the information about the scenarios of the patients care. These data can be easily exported to an external database for tracking and analysis.

In this study, we focused on the optimization of a single Work Package (WP). The principle is the same for all other WPs. However, we aim in future work to optimize our solution for all WP of the same unit or for all units of the nursing home, taking into account the potential interactions between units. The system may also include other tasks performed in a nursing home around the care of the elderly: housekeeping, catering, entertainment, meeting time and cooperation between teams, etc.

We will also focus in our future work on the establishment of a dynamic relationship between these two modules, to ensure the system robustness in case of disturbance (new constraints, delay, regression of the health of residents, etc.). In this case, the tool has to adapt its behavior in real time taking into account the new data.

\section{REFERENCES}

1. Daknou, A., Distributed agent based architecture to optimize the management of patients at the emergency department in hospitals, in LAGIS FRE 3303. 2011, Ecole Centrale de Lille, France: Villeneuve d'Ascq. p. 204.

2. Ernst, A.T., et al., Staff scheduling and rostering: A review of applications, methods and models. European Journal of Operational Research, 2004. 153: p. 3-27.

3. Cheang, B., et al., Nurse rostering problems - a bibliographic survey. European Journal of Operational Research, 2003. 151: p. 447-460.

4. Burke, E., et al., The State of the Art of Nurse Rostering. Journal of Scheduling, 2004. 7(6): p. 441--499. 
5. Hadwan, M., et al., A harmony search algorithm for nurse rostering problems. Information Sciences, 2013. 233: p. $126-140$.

6. Chandoul, W., et al., Evolutionary Approach for Multi-Objective Scheduling in Surgical Unit, in GISEH 2012. 2012: Québec, Canada.

7. Shopova, E.G. and N.G. Vaklieva-Bancheva, BASIC-A genetic algorithm for engineering problems solution.Computers and Chemical Engineering, 2006. 30: p. 1293-1309.

8. Hassan, T., Logistique hospitalière : organisation de la chaîne logistique pharmaceutique aval et optimisation des flux de consommables et des matériels à usage unique, in LIESP - Laboratoire d'Informatique pour l'Entreprise et les Systèmes de Production. 2006, UNIVERSITÉ CLAUDE BERNARD - LYON 1: Lyon. p. 293.

9. Di Martinelly, C., Proposition of a framework to reengineer and evaluate the hospital supply chain, in LIESP Laboratoire d'Informatique pour l'Entreprise et les Systèmes de Production (France), CREGI : Centre de Recherche En Gestion Industrielle -FUCaM (Belgique). 2008, Facultés universitaires catholiques de Mons Belgique: Lyon.

10. Farouk, I.E.I., T. Abdennebi, and J. Fouad, Modeling and simulation of hospital supply chain: state of the art and research perspectives, in International Conference on Logistics (LOGISTIQUA)2011: Hammamet, Tunisie. p. 287 $-291$.

11. Ahmed, S. and M.N. Karsiti, Multiagent Systems. Ahmed, S Karsiti, M N ed. 2009: I-Tech.

12. Bordini, R.H., et al., Multi-agent programming languages, Platforms and Applications. International Book Series, ed. G. Weiss. 2005: Springer.

13. Kehe, W., Z. Huan, and M. Gang, Design and implementation of ARIS methodology-based process modeling and management platform, in Energy Procedia. 2011. p. 430-436.

14. Sheer, A.W., ARIS - Business Process Modelling. 2002: Springer.

15. Huang, S.H., S.K. Sheoran, and H. Keskar, Computer-assisted supply chain configuration based on supply chain operations reference (SCOR) model.Computers \& Industrial Engineering, 2005. 48(2): p. 377-394.

16. Gourgand, M. and P. Keller, Conception d'un environnement de modélisation des systèmes de production, in Congrès International de Génie Industriel. 1991: Tours, France.

17. Doumeingts, G., B. Vallespir, and D. Chen, GRAI Grid Decisional Modelling, in Handbook on Architectures of Information Systems. 1998. p. 313-337.

18. Chinosi, M. and A. Trombetta, BPMN: An introduction to the standard. Computer Standards \& Interfaces, 2012. 34(1): p. 124-134.

19. Marquardt, W. and M. Nagl, Workflow and information centered support of design processes-the IMPROVE perspective. Computers and Chemical Engineering, 2004. 29: p. 65-82.

20. Liu, et al., Comparison between Collaborative Business Process tools, in Fifth International Conference on Research Challenges in Information Science (RCIS). 2011: Gosier. p. 1 - 6.

21. Collette, Y. and P. Siarry, Optimisation multiobjectif, ed. EYROLLES. 2002.

22. Dréo, J., et al., Métaheuristiques pour l'optimisation difficile. 2003: EYROLLS.

23. Zgaya, H., Conception et optimisation distribuée d'un système d'information d'aide à la mobilité urbaine : Une approche multi-agent pour la recherche et la composition des services liés au transport, in LAGIS FRE CNRS 3303. 2007, Ecole Centrale de Lille: Villeneuve d'Ascq, France.

24. Novák, V., Reasoning about mathematical fuzzylogic and its future. Fuzzy Sets and Systems, 2012. 192: p. 2544.

25. Zadeh, L.A., The role of fuzzylogic in the management of uncertainty in expert systems. Fuzzy Sets and Systems, 1983. 11(1-3): p. 197-198.

26. Caux, C., H. Pierreval, and M.-C. Portmann, Genetic algorithms and scheduling problems, in Journées du GT3. 1994: Toulouse, FRANCE. p. 409-443.

27. Pierreval, H., et al., Evolutionary approaches to the design and organization of manufacturing systems. Computers \& Industrial Engineering, 2003. 44(3): p. 339-364.

28. Renner, G. and A. Ekárt, Genetic algorithms in computer aided design. Computer-Aided Design, 2003. 35(8): p. 709-726.

29. Zgaya, H., H. Hammadi, and K. Ghedira, A migration strategy of mobile agents for the transport network applications. International journal, Mathematics and Computers in Simulation (Elsevier), 2008. 76(5-6): p. 345362. 